\title{
ESTIMATING SOLAR RADIATION IN IKEJA AND PORT HARCOURT VIA CORRELATION WITH RELATIVE HUMIDITY AND TEMPERATURE
}

\author{
O. T. KOLEBAJE, A. IKUSIKA \& P. AKINYEMI \\ Department of Physics, Adeyemi College of Education, Ondo, Nigeria
}

\begin{abstract}
Relative humidity and temperature data are more readily available to obtain from observatories than sunshine hour data. In this work, 10 years (1986-1987, 1990-1997) monthly average measurement of relative solar radiation, daily temperature range, relative humidity and the ratio of minimum to maximum temperature were used to establish the coefficient of eight models for estimating solar radiation in Ikeja and Port Harcourt. Coefficient of correlation (R), Mean Bias Error (MBE), Root Mean Square Error (RMSE), Mean Percentage Error (MPE), t-statistic and the rank score were used as performance indicators. In Port Harcourt, the equation producing the best result with MBE, RMSE, MPE and $\mathrm{t}$-statistic value of $-0.1078,0.9850,-0.4373 \%$ and 0.3653 , respectively, is given by:
\end{abstract}

$$
\frac{R_{s}}{R_{o}}=3.266-0.306(\overline{R H})^{0.5}
$$

In Ikeja, the equation producing the best estimation with MBE, RMSE, MPE and t-statistic value of $0.1590,1.0110,2.0559 \%$ and 0.5281 , respectively, is given by:

$$
\frac{R_{s}}{R_{o}}=2.042-2.136(\theta)
$$

Keywords: empirical model, global solar radiation, relative humidity, temperature.

\section{INTRODUCTION}

The energy transferred from the sun in the form of radiant energy to the earth's surface is called solar radiation. Global solar radiation is the combination of normal direct solar radiation and the angular or oblique diffuse solar radiation received on a horizontal plane. It is very germane to the earth's ecosystem as it provides the energy for photosynthesis in plants. It also affects both air and soil temperature, influences the rate of evaporation and regulates weather and climate.

As different sites on the earth surface have varying solar energy potential, an understanding of this variation is important in choosing solar equipment for socio-economic uses such as irrigation, electricity generation, and so on. Effective harnessing and utilization of solar radiation is vital to solving the world's energy crisis and climate change problem [1].

However, this solar radiation data may not be available where it is needed as it has reported that the global ratio of weather stations collecting solar radiation data relative to those 
collecting temperature data is about 1:500 [2]. Also, solar radiation measuring equipments are expensive to purchase and maintain for each site of interest.

A viable alternative to providing solar radiation data is by employing various solar radiation models. Using metrological variables such as relative sunshine hours, cloudiness and temperature, models have been developed by [3-11].

The objective of this study is to assess the performance (annually and seasonally) of eight solar radiation empirical formulas in Ikeja and Port Harcourt, Nigeria.

\section{METHODOLOGY}

$$
\begin{gathered}
\frac{R_{s}}{R_{o}}=a_{1}+b_{1} \Delta \mathrm{T}^{0.5} \\
\frac{R_{s}}{R_{o}}=a_{2}+b_{2} \frac{\Delta T}{N} \\
\frac{R_{s}}{R_{o}}=a_{3}+b_{3} \overline{R H} \\
\frac{R_{s}}{R_{o}}=a_{4}+b_{4}(\theta) \\
\frac{R_{s}}{R_{o}}=a_{5}+b_{5} \overline{R H}+c_{5}(\theta)+d_{5}(\Delta T) \\
\frac{R_{s}}{R_{o}}=a_{6}+b_{6}(\overline{R H})^{0.5} \\
\frac{R_{s}}{R_{o}}=a_{7}+b_{7}\left(\frac{\Delta T+\overline{R H}}{N}\right)^{0.5} \\
+b_{8}\left(\frac{\Delta T+\overline{R H}}{N}\right)^{0.5}+c_{8}(\theta)
\end{gathered}
$$

Where $R_{s}$ is the global solar radiation in $\mathrm{MJm}^{-2} \mathrm{day}^{-1}, R_{o}$ is the Extra-terrestrial radiation in $\mathrm{MJm}^{-2}$ day $^{-1}, N$ is the daylight hour in hours, $\Delta T$ is the difference between maximum temperature and minimum temperature values, $\overline{R H}$ is the relative humidity and $\theta$ is the ratio of minimum temperature to maximum temperature. $a_{i}, b_{i}, c_{i}$ and $d_{i}$ for $i=1,2,3, \ldots, 8$ are constants which are to be determined by regression analysis.

Hargreaves and Samani [5] developed eqn (1) as an empirical equation that took the form of a linear regression between the relative incoming solar radiation and the square root of the difference between maximum and minimum temperature. Garcia [8] developed eqn (2) as an adaptation of the common Angstrom-Prescott model to estimate incoming solar radiation in Peru. 
Equations (3) have been developed to investigate the relationship between solar radiation and relative humidity [12]. Equation (4) compares relative solar radiation and the ratio of the minimum temperature to the maximum temperature.

Equations (5-8) are newly proposed empirical relations to be employed and tested in this paper. Equations (5-8) are formed based on the assumption that there is a strong relationship between global solar radiation and a combination of relative humidity, difference between minimum and maximum temperature and ratio of minimum temperature to maximum temperature. Equation (7) is based on the relationship between solar radiation and relative humidity as an adaptation of the Hargreaves model (eqn (1)).

\subsection{Study area and data measurement}

The study site is located in Ikeja and Port Harcourt, Nigeria. They are located in the extreme southern region of Nigeria, very close to the Atlantic Ocean. Ikeja and Port Harcourt is in the rainforest and mangrove region characterized by thick vegetation with very high canopies. With an annual average temperature of $23.0^{\circ} \mathrm{C}\left(73.4^{\circ} \mathrm{F}\right)$, . The warmest months are from February to April, where daytime temperatures can exceed $29^{\circ} \mathrm{C}\left(84.2^{\circ} \mathrm{F}\right)$.

Rainfall season is often throughout the year with mean annual falls ranging between $1,500 \mathrm{~mm}$ and $2,300 \mathrm{~mm}$. They are characterized by regular torrential showers known in many tropical regions. The humidity is generally low and the Harmattan (hot, dry northeast trade wind), a cold and fairly dusty wind is experienced between December and February. There are two major seasons in these stations namely the wet and dry seasons. The rainy season is from April to November while the dry season is from December to February.

The maximum and minimum thermometers were used to measure the highest and lowest temperature reached by air in each day at the observatory. These thermometers were kept at a height of $1.5 \mathrm{~m}$ above the ground in a white wooden-louvered shelter called Stevenson screen. Maximum and minimum thermometers are liquid in glass thermometers used for determining daily maximum and minimum temperatures. Sunshine hour was measured using the Campbell-stokes sunshine recorder. The device is designed to record the hours of bright sunshine which will burn a hole through the card.

18 years of monthly mean hourly solar radiation, sunshine hour, minimum and maximum temperature, relative humidity data were collected and used in this study. 15 years of data (1981-1995) were used for obtaining the regression coefficients $a_{i}, b_{i}, c_{i}$ and $d_{i}$ for $i=1,2,3, \ldots, 15$ while 3 years (1996-1998) was used for testing the performance of the models.

The site-specific inputs for the calculation of extra-terrestrial solar radiation are latitude and sunset hour angle. The extra-terrestrial daily solar radiation (in $\mathrm{MJm}^{-2} \mathrm{day}^{-1}$ ) is determined by the sets of equations given below [13].

$$
\begin{gathered}
R_{o}=\frac{24(60)}{\pi} G_{s c} d_{r}\left[\omega_{s} \sin \varphi \sin \delta+\cos \varphi \cos \delta \sin \omega_{s}\right] \\
d_{r}=1+0.033 \cos \left(\frac{2 \pi J}{365}\right)
\end{gathered}
$$




$$
\begin{gathered}
\delta=0.409 \sin \left(\frac{2 \pi J}{365}-1.39\right) \\
\omega_{s}=\cos ^{-1}(-\tan \varphi \tan \delta)
\end{gathered}
$$

Where $R_{o}$ is the extra-terrestrial radiation $\left(\mathrm{MJm}^{-2} \mathrm{~d}^{-1}\right)$.

$G_{s c}$, solar constant $=0.082 \mathrm{MJm}^{-2} \mathrm{day}^{-1}$,

$d_{r}$ is the inverse relative distance Earth-Sun,

$\omega_{s}$ is the sunset hour angle (radians),

$\varphi$ is the latitude (radians),

$\delta$ is the solar declination (radians),

$J$ is the Number of the day in the year between 1(1 January) and 365 or 366 (31 December).

The daylight hours $\mathrm{N}$ (hours) is also calculated using the equation given below [13].

$$
N=\frac{24}{\pi} \omega_{s}
$$

The extra-terrestrial radiation and daylight hours for stations used in this research were calculated and they are shown in the Table 1 below.

Table 1: Extra-terrestrial radiation $\left(\mathrm{MJm}^{-2} \mathrm{day}^{-1}\right)$ and Daylight hours (hours) of the locations of study.

\begin{tabular}{lcccc}
\hline & \multicolumn{2}{c}{ Extra-terrestrial rad } & \multicolumn{2}{c}{ Daylight hours } \\
\hline Month & P/Harcourt & Ikeja & P/Harcourt & Ikeja \\
\hline January & 34.3177 & 33.5460 & 11.7571 & 11.6649 \\
February & 36.1183 & 35.5766 & 11.8493 & 11.7922 \\
March & 37.4901 & 37.2984 & 11.9744 & 11.9646 \\
April & 37.4004 & 37.5936 & 12.1082 & 12.1493 \\
May & 36.1869 & 36.6738 & 12.2186 & 12.3016 \\
June & 35.2664 & 35.8817 & 12.2724 & 12.3757 \\
July & 35.5698 & 36.1215 & 12.2462 & 12.3396 \\
August & 36.6801 & 36.9865 & 12.1504 & 12.2075 \\
September & 37.2106 & 37.1552 & 12.0212 & 12.0292 \\
October & 36.2928 & 35.8598 & 11.8877 & 11.8451 \\
November & 34.5579 & 33.8411 & 11.7784 & 11.6943 \\
December & 33.5718 & 32.7346 & 11.7274 & 11.6240 \\
\hline
\end{tabular}




\subsection{Acquisition of data and instrumentation}

The data used in this study was collected from the Nigerian Metrological Agency (NIMET), Oshodi, Lagos which has been given the mandate to collect meteorological data for climatology, agricultural and aviation purposes in the country.

At the Nigerian meteorological agency, global solar radiation is measured through the use of the Gunn Bellani radiometer (GB) which is a simple, cheap and easy to maintain instrument commonly used in solar radiation estimation and evaporation studies.

The instrument provides a time-integrated assessment of radiation falling on a black body by measuring the volume of liquid distilled by the radiation. It is available in two forms: water filled for daily radiation of up to $6.28 \mathrm{MJm}^{-2}$; and alcohol filled for daily radiation of up to $37.68 \mathrm{MJm}^{-2}$. It requires neither powering nor any special skill to operate, and has been found suitable for field estimation of daily total radiation.

The liquid is contained in a thin-walled copper sphere blackened externally. Sealed into this, with its upper end above liquid level, is the distillation tube. The latter collects liquid distilled from the bulb in its lower section which is graduated in $0.1 \mathrm{~mL}$ divisions. The bulb holds about $42 \mathrm{~mL}$ of the working fluid. Initially, the liquid is transferred to the copper sphere by inverting the instrument, and the level remaining in the graduated receiver is noted. When exposed to solar radiation, the fluid in the blackened copper sphere vaporizes and condenses in the graduated receiver. Periodically, or at the end of each day, radiation level is recorded. Folayan [14] calibrated GB readings with pyranometer readings and came up with a conversion factor which may be mathematically expressed as: $1 \mathrm{ml}_{G B}=1.357( \pm 0.176) \mathrm{MJm}^{-2}$.

\subsection{Treatment of data and error analysis}

Models were developed for the locations under study by using 10 years (1986-1987, 1990-1997) and 3 years (1998-2000) for model validation.

In this study, the performance indicators used are the Mean Bias Error (MBE), Root Mean Square Error (RMSE), Mean Percentage Error (MPE) and the $t$-statistic test:

$$
\begin{gathered}
\mathrm{MBE}=\left[\sum_{1}^{\mathrm{n}}\left(\mathrm{R}_{\text {est }}-\mathrm{R}_{\mathrm{obs}}\right)\right] / \mathrm{n} \\
\mathrm{RMSE}=\left[\sum_{1}^{\mathrm{n}}\left(\mathrm{R}_{\mathrm{est}}-\mathrm{R}_{\mathrm{obs}}\right)^{2} / \mathrm{n}\right]^{1 / 2} \\
\mathrm{MPE}=\left[\sum_{1}^{\mathrm{n}}\left(\frac{\mathrm{R}_{\mathrm{obs}}-\mathrm{R}_{\text {est }}}{\mathrm{R}_{\mathrm{obs}}} \times 100\right)\right] / \mathrm{n}
\end{gathered}
$$

Where $R_{o b s}$ and $R_{e s t}$ are, respectively, the observed and estimated values of global solar radiation and $n$ is the number of observations used. Generally, the lower the MBE, RMSE and MPE, the better the model. A positive MBE or MPE value indicates overestimation in calculated values, while a negative MBE or MPE value indicate underestimation. The MBE provides information about the long-term performance of the model while the RMSE provides information about the short-term performance of the model. 
Low values of RMSE are desirable, but few errors in the sum can produce a significant increase in the indicator. Low values of MBE are desirable, but overestimation of an individual data element will cancel underestimation in a separate observation. It is also possible to have large RMSE values at the same time a small MBE or vice versa. Therefore, the use of RMSE and MBE as indicators is not adequate for the evaluation of model performance [15]

The $t$-statistic is used in conjunction with the MBE and RMSE to test model performance more reliably [16]. The $t$-statistic is given by

$$
t=\sqrt{\left((\mathrm{N}-1) \mathrm{MBE}^{2}\right) /\left(\mathrm{RMSE}^{2}-\mathrm{MBE}^{2}\right)}
$$

The estimates from the model will only be statistically significant if the calculated $t$ is less than a critical $t$-value obtained from standard statistical tables.

The best performing models were determined using a ranking method. The MBE and RMSE were normalized by dividing each by the mean of the measured dataset. A rank score was obtained for each model. The model with the lowest rank score received the highest ranking.

$$
\text { RankScore }=\frac{\operatorname{Abs}(\mathrm{MBE})}{\text { Mean }}+\frac{\mathrm{RMSE}}{\text { Mean }}+t
$$

\section{RESULTS AND DISCUSSIONS}

The average monthly values of the sunshine hour, global radiation, and maximum and minimum temperature data for Ikeja and Port Harcourt stations were calculated. Regression coefficients for each of the models were developed from the dataset of monthly mean of $R_{s} / R_{0}, \overline{R H}, \theta, \Delta T^{0.5}$ and $\Delta T / N$, and they are stated below in Tables 2 and 3, respectively, for Port Harcourt and Ikeja:

Tables 4 and 5, respectively, gives the coefficient of correlation (R), MBE, RMSE, MPE, $t$-statistic value, the Rank Score and the Rank for each of the eight models developed for Port Harcourt and Ikeja. From Table 4, the correlation coefficients for the eight models developed

Table 2: Regression coefficients for Port Harcourt.

\begin{tabular}{lccccc}
\hline Equation $(\boldsymbol{i})$ & $\boldsymbol{R}$ & $\boldsymbol{a}_{\boldsymbol{i}}$ & $\boldsymbol{b}_{\boldsymbol{i}}$ & $\boldsymbol{c}_{\boldsymbol{i}}$ & $\boldsymbol{d}_{\boldsymbol{i}}$ \\
\hline $\mathbf{1}$ & 0.926 & -0.141 & 0.210 & - & - \\
$\mathbf{2}$ & 0.913 & 0.185 & 0.399 & - & - \\
$\mathbf{3}$ & 0.896 & 1.875 & 0.017 & - & - \\
$\mathbf{4}$ & 0.907 & 1.479 & -1.386 & - & - \\
$\mathbf{5}$ & 0.876 & 0.777 & -0.018 & 1.321 & 0.030 \\
$\mathbf{6}$ & 0.923 & 3.266 & -0.306 & - & - \\
$\mathbf{7}$ & 0.794 & 5.981 & -1.991 & - & - \\
$\mathbf{8}$ & 0.841 & 2.931 & -0.570 & -1.214 & - \\
\hline
\end{tabular}


Table 3: Regression coefficients for Ikeja.

\begin{tabular}{lccccc}
\hline Equation $(\boldsymbol{i})$ & $\boldsymbol{R}$ & $\boldsymbol{a}_{\boldsymbol{i}}$ & $\boldsymbol{b}_{\boldsymbol{i}}$ & $\boldsymbol{c}_{\boldsymbol{i}}$ & $\boldsymbol{d}_{\boldsymbol{i}}$ \\
\hline $\mathbf{1}$ & 0.941 & -0.318 & 0.271 & - & - \\
$\mathbf{2}$ & 0.933 & 0.094 & 0.523 & - & - \\
$\mathbf{3}$ & 0.869 & 2.024 & -0.019 & - & - \\
$\mathbf{4}$ & 0.914 & 2.042 & -2.136 & - & - \\
$\mathbf{5}$ & 0.929 & -2.686 & 0.001 & 2.834 & 0.115 \\
$\mathbf{6}$ & 0.818 & 3.614 & -0.351 & - & - \\
$\mathbf{7}$ & 0.764 & 2.281 & -0.675 & - & - \\
$\mathbf{8}$ & 0.879 & 3.886 & -0.673 & -2.135 & - \\
\hline
\end{tabular}

Table 4: Performance test result and ranking of models for Port Harcourt.

\begin{tabular}{lccccccc}
\hline & & \multicolumn{7}{c}{ Performance Indicators } & & \\
\cline { 3 - 6 } Equation & $\mathrm{R}$ & MBE & RMSE & MPE (\%) & $t$ & Rank Score & Rank \\
\hline Model 1 & 0.926 & -0.4306 & 1.1010 & -1.8116 & 1.4096 & 1.4944 & 6 \\
Model 2 & 0.913 & -0.5258 & 1.1420 & -2.5116 & 1.7202 & 1.8126 & 7 \\
Model 3 & 0.896 & -0.2002 & 1.2685 & -1.1496 & 0.5301 & 0.6115 & 2 \\
Model 4 & 0.907 & -0.6193 & 1.2698 & -2.7971 & 1.8528 & 1.9575 & 8 \\
Model 5 & 0.876 & 0.4424 & 1.2885 & 2.8799 & 1.2123 & 1.3083 & 4 \\
Model 6 & 0.923 & -0.1078 & 0.9850 & -0.4373 & 0.3653 & 0.4258 & 1 \\
Model 7 & 0.794 & 0.6193 & 1.6939 & 3.9494 & 1.3029 & 1.4311 & 5 \\
Model 8 & 0.841 & -0.3663 & 1.3966 & -1.5154 & 0.9015 & 0.9992 & 3 \\
\hline
\end{tabular}

for Port Harcourt ranged from $0.794-0.926$. This indicates a high positive correlation between the estimated and the measured or observed solar radiation values. All the models developed for Port Harcourt except Model 5 and Model 7 underestimated measured solar radiation as the produced negative MBE and MPE values. Model 6 gave the best MBE and MPE values of $-0.1078 \%$ and $-0.4373 \%$, respectively, while Model 7 produced the poorest MBE and MPE values of $0.6193 \%$ and $3.9494 \%$, respectively. The lowest RMSE value of 0.9850 was recorded for Model 6 while Model 7 produced the highest RMSE value of 1.6939. The critical value for the t-test conducted is 1.796 at $95 \%$ confidence level. All the models except Model 4 gave $t$-value that was less than the critical value which means that all the models except Model 4 produced estimation that was statistically significant. All the models except Models 7 and 4 are recommended for estimating global solar radiation in Port Harcourt with Model 6 producing the best result.

From Table 5, the correlation coefficients for the eight models developed for Ikeja ranged from 0.764 to 0.941 . This indicates a high positive correlation between the estimated and the measured or observed solar radiation values. All the models produced a positive MBE and MPE value which indicates that they all overestimated the measured global solar radiation 
Table 5: Performance test result and ranking of models for Ikeja.

\begin{tabular}{lccccccc}
\hline & & \multicolumn{5}{c}{ Performance Indicators } & \\
\cline { 3 - 6 } Equation & $\mathrm{R}$ & MBE & RMSE & MPE $(\%)$ & $t$ & Rank Score & Rank \\
\hline Model 1 & 0.941 & 0.3468 & 0.8870 & 3.0847 & 1.4087 & 1.4978 & 3 \\
Model 2 & 0.933 & 0.4014 & 0.9622 & 3.5957 & 1.5223 & 1.6208 & 4 \\
Model 3 & 0.869 & 1.6664 & 2.0520 & 13.4271 & 4.6161 & 4.8846 & 8 \\
Model 4 & 0.914 & 0.1590 & 1.0110 & 2.0559 & 0.5281 & 0.6125 & 1 \\
Model 5 & 0.929 & 0.4128 & 0.9888 & 3.5857 & 1.5236 & 1.6248 & 5 \\
Model 6 & 0.818 & 0.9667 & 1.7854 & 8.0060 & 2.1359 & 2.3346 & 6 \\
Model 7 & 0.764 & 1.2313 & 2.1181 & 10.0042 & 2.3695 & 2.6113 & 7 \\
Model 8 & 0.879 & 0.4126 & 1.2932 & 3.4516 & 1.1165 & 1.2396 & 2 \\
\hline
\end{tabular}

data for Ikeja. Model 4 produced the best MBE and MPE values of $0.1590 \%$ and $2.0559 \%$, respectively. The poorest MBE and MPE values of $1.6664 \%$ and $13.4271 \%$ respectively were observed for Model 3. The solely relative humidity-based models (Model 3 and Model 6) did not perform well as they produced the poorest MBE and MPE values. The lowest and the highest RMSE values of 0.8870 and 2.1181 were recorded for Model 1 and Model 7, respectively. All the models except Models 3, 6 and 7 are not recommended for estimating global solar radiation in Ikeja as they produced $t$-values greater than the critical value of 1.796 . According to the rank score, Model 4 with MBE, RMSE, MPE and $t$-statistic value of 0.1590, $1.0110,2.0559 \%$ and 0.5281 , respectively, produced the best estimation in Ikeja. The ability of the models in estimating monthly radiation values are compared in Figs 1 and 2, respectively, for Port Harcourt and Ikeja. The figures show that the models follow the same trend and are close to the measured global solar radiation values obtained from the observatory for Port Harcourt and Ikeja stations.

\section{CONCLUSION AND RECOMMENDATION}

In this work, 10 years monthly average values of relative solar radiation, daily temperature range, relative humidity and the ratio of minimum to maximum temperature were used to develop coefficients for empirical models for the estimation of global solar radiation in Port Harcourt, Ikeja, Jos and Sokoto stations in Nigeria. The models used all relative humidity and temperature-based models.

Comparison of the predictive efficiency of these five models is carried out using the coefficient of correlation (R), MBE, RMSE, MPE, $t$-statistic and the rank score as performance indicators. The rank score combines the MBE and RMSE to produce a value that has the lowest value for the best model and highest value for the poorest model. All the models except Models 7 and 4 are recommended for estimating global solar radiation in Port Harcourt with Model 6 producing the best result. In Ikeja, Model 4 with MBE, RMSE, MPE and t-statistic value of $0.1590,1.0110,2.0559 \%$ and 0.5281 respectively produced the best estimation. Also, Models 3, 6 and 7 are not recommended for estimating global solar radiation in Ikeja as they produced t-values greater than the critical value of 1.796.

The work has been seriously limited by the non-availability of meteorological data over a long period of years for the stations used. Hence, effort should be made to obtain more than 


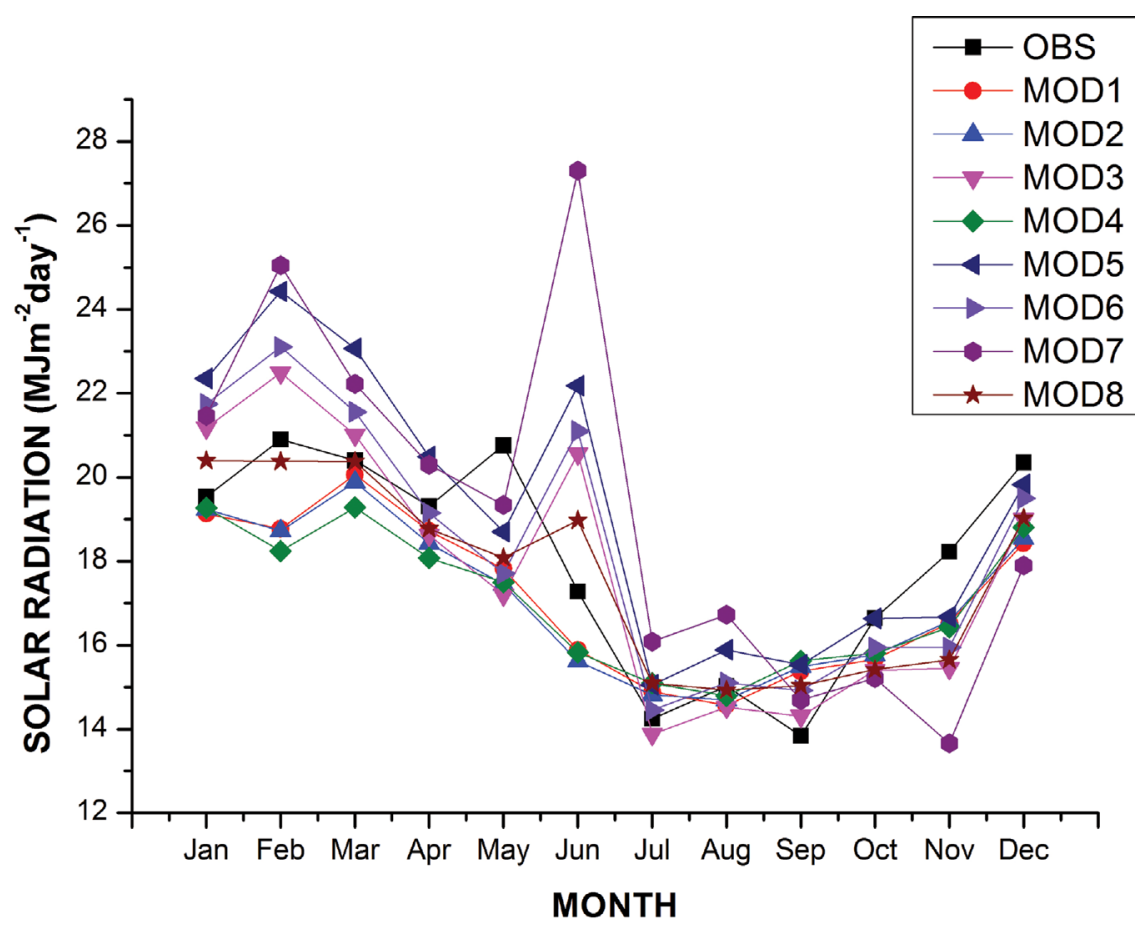

Figure 1: Trend of monthly estimates compared with observed for Port Harcourt.

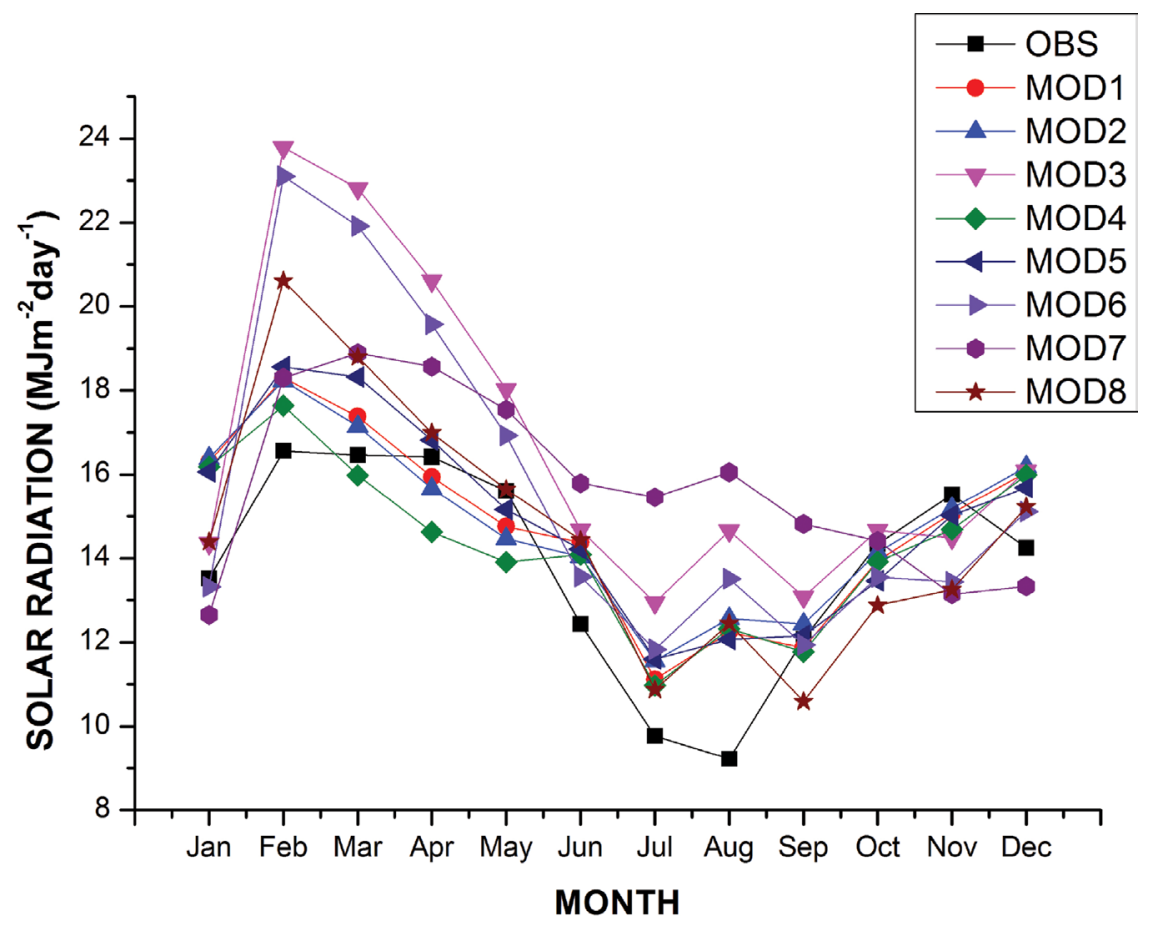

Figure 2: Trend of monthly estimates compared with observed for Ikeja. 
20 years data for the stations used in this study and other stations in Nigeria. This will help improve on the estimations produced by these empirical models.

\section{REFERENCES}

[1] Van Boxel, J.H., Modelling Global Radiation for the Portofino Area in Italy, Institute for Biodiversity and Ecosystem Dynamics IBED, 2002. http://dx.doi.org/10.1016/S0168-1923(98)00126-9

[2] Thornton, P.E. \& Running, S.W., An improved algorithm for estimating incident daily solar radiation from measurements of temperature, humidity and precipitation. Agricultural and Forest Meteorology, 93, pp. 211-228, 1999.

[3] Angstrom, A., Solar and terrestrial radiation. Quarterly Journal of the Royal Meteorological Society, 50, pp. 121-125, 1924. http://dx.doi.org/10.1002/qj.49705021008

[4] Prescott, J.A., Evaporation from a water surface in relation to solar radiation. Transaction of the Royal Society of South Australia, 64, pp. 114-125, 1940.

[5] Hargreaves, G. \& Samani, Z., Estimating potential evapotranspiration. Journal of Irrigation and Drainage Engineering, 108, pp. 225-230, 1982.

[6] Bristow, K. \& Campbell, G., On the relationship between incoming solar radiation and daily maximum and minimum temperature. Agricultural and Forest Meteorology, 31, pp. 159-166, 1984. http://dx.doi.org/10.1016/0168-1923(84)90017-0

[7] Fagbenle, R.O., Estimation of total solar radiation in nigeria using meteorological data. Nigerian Journal Renewable Energy, 14, pp. 1-10, 1990.

[8] Garcia, J.V., Principios F'isicos de la Climatolog'ia, Ediciones UNALM Universidad Nacional Agraria La Molina: Lima, Peru, 1994.

[9] Mahmood, R. \& Hubbard, K.G., Effect of time of temperature observation and estimation of daily solar radiation for the northern great plains, USA. Agronomy Journal, 94, pp. 723-733, 2002.

http://dx.doi.org/10.2134/agronj2002.7230

[10] Udo, S.O., Contribution to the relationship between solar radiation and sunshine duration in the topics: a case study of experimental data at Ilorin, Nigeria. Turkish Journal of Physics, 26, pp. 229-236, 2002.

[11] Akpabio, L.E., Modelling global solar radiation for a tropical location: Onne, Nigeria. Turkish Journal of Physics, 29, pp. 63-68, 2002.

[12] Mubiru, J., Banda, E.J.K.E., D’Ujanga, F. \& Senyonga, T., Assessing the performance of global solar radiation empirical formulations in Kampala, Uganda. Theoretical and Applied Climatology, 87, pp. 179-184, 2007. http://dx.doi.org/10.1007/s00704-005-0196-2

[13] Allen E., Crop Evapotranspiration: Guidelines for Computing Crop Water Requirements, FAO Irrigation and Drainage Paper, 1998.

[14] Folayan, C., Estimation of global solar radiation bound for some nigeria cities. Nigeria Journal of Solar Energy, 14, pp. 3-10, 1988.

[15] Jacovides, C.P., Statistical procedures for the evaluation of evapotranspiration computing models. Agricultural Water Management, 27, pp. 365-371, 1995.

http://dx.doi.org/10.1016/0378-3774(95)01152-9

[16] Almorox, J., Benito, M. \& Hontoria, C., Estimation of monthly Angstrom-Prescott equation coefficients from measured daily data. Renew Energy, 30, pp. 931-936, 2005. http://dx.doi.org/10.1016/j.renene.2004.08.002 